\title{
PROFIL PITIRIASIS VERSIKOLOR DI POLIKLINIK KULIT DAN KELAMIN RSUP PROF. DR. R.D KANDOU MANADO PERIODE JANUARI - DESEMBER 2012
}

\author{
${ }^{1}$ Silvia Nathalia \\ ${ }^{2}$ Nurdjannah J. Niode \\ ${ }^{2}$ Herry E.J. Pandaleke \\ ${ }^{1}$ Kandidat skripsi Fakultas Kedokteran Universitas Sam Ratulangi Manado \\ ${ }^{2}$ Bagian/SMF Kulit dan Kelamin RSUP Prof.Dr. R.D. Kandou Manado \\ Email : thepianiste@yahoo.co.id
}

\begin{abstract}
Pityriasis versicolor is a superficial fungal infection of the epidermal layer caused by Malassezia furfur or Pityrosporum orbiculare. This infection is chronic, mild, and usually without inflammation. Pityriasis versicolor infects the face, neck, torso, upper arms, underarms, thighs, andgroin. Skin disorders are very superficial and pityriasis versicolor is most commonly found in the body. The disorder is seen a spatches of colorful irregular shape to a regular, well defined to diffuse. The disorder is usually asymptomatic so that sometimes people do not know they have been infected. This study aims to determine profil of pityriasis versicolor at dermatovenereology clinic of Prof. Dr. R. D. Kandou General Hospital Manado periods January- December 2012. This retrospective descriptivestudy is based on the number of cases, gender, age, occupation, color of lesion, location of lesion, and the type of treatment. The results of this study showed that out of the 50 pityriasis versicolor cases (1.24\%), male as the most infected gender (74\%), along with the age group 25-44years (28\%), the most job is civil servant (24\%), and with hypopigmented lesions as the most types found (78\%). The most frequent location of lesion is a combination of several places such as the face, body and extremities (60\%), and the most used treatment is a combination therapy of oral and topical anti fungal (72\%).
\end{abstract}

Keywords: pityriasis versicolor

Abstrak: Pitiriasis versikolor adalah infeksi jamur superfisial pada lapisan tanduk kulit yang disebabkan oleh Malassezia furfur atau Pityrosporum orbiculare. Infeksi ini bersifat menahun, ringan, dan biasanya tanpa peradangan. Pitiriasis versikolor mengenai muka, leher, badan, lengan atas, ketiak, paha, dan lipat paha. Kelainan kulit pitiriasis versikolor sangat superfisial dan ditemukan terutama di badan. Kelainan ini terlihat sebagai bercak-bercak berwarna-warni bentuk tidak teratur sampai teratur, batas jelas sampai difus. Kelainan biasanya asimptomatik sehingga adakalanya penderita tidak mengetahui bahwa ia berpenyakit tersebut. Tujuan penelitian ini adalah untuk mengetahui profil pitiriasis versikolor di Poliklinik Kulit dan Kelamin RSUP Prof. DR. R.D. Kandou Manado periode Januari-Desember 2012. Penelitian ini 
merupakan penelitian deskriptif retrospektif berdasarkan jumlah kasus, jenis kelamin, umur, pekerjaan, warna lesi, lokasi lesi, dan jenis pengobatan. Hasil penelitian ini menunjukkan bahwa dari 50 kasus pitiriasis versikolor ( 1,24\% ) terbanyak adalah jenis kelamin laki-laki (74\%), kelompok umur 25-44 tahun (28\%), pekerjaan yang terbanyak adalah PNS (24\%), jenis lesi paling banyak lesi hipopigmentasi (78\%), lokasi lesi paling sering yaitu kombinasi yang terdapat dibeberapa tempat seperti wajah, badan dan ekstremitas ( 60\%), dan pengobatan yang paling banyak adalah terapi kombinasi antijamur oral dan antijamur topikal (72\%).

Kata kunci: pitiriasis versikolor

Pitiriasis versikolor adalah penyakit universal tapi lebih banyak dijumpai di daerah tropis oleh karena tingginya temperatur dan kelembaban.Penyakit ini juga ditemukan pada semua ras. Tidak ada perbedaan antara pria dan wanita, walaupun di Amerika Serikat dilaporkan bahwa penderita berusia 20-30 tahun dengan perbandingan $1,09 \%$ pria dan $0,6 \%$ wanita. $^{1}$

Di Indonesia, insidensinya belum akurat dan sulit diakses karena banyak penderita yang tidak berobat ke petugas medis namun di perkirakan 40-50\% dari populasi di negara tropis terkena penyakit ini. Di Jakarta golongan penyakit ini sepanjang masa selalu menempati urutan kedua setelah dermaititis. Di daerah lain, seperti Padang, Bandung, Semarang, Surabaya dan Manado keadaannya kurang lebih sama, yakni menempati urutan ke-2 sampai ke-4 terbanyak dibandingkan golongan penyakit lainnya. $^{2}$

Kelainan kulit pitiriasis versikolor sangat superfisial dan ditemukan terutama di badan. Kelainan ini terlihat sebagai bercak-bercak berwarna-warni bentuk tidak teratur sampai teratur, batas jelas sampai difus. Kelainan biasanya asimptomatik sehingga adakalanya penderita tidak mengetahui bahwa ia berpenyakit tersebut.

Kadang-kadang penderita dapat merasakan gatal ringan, yang merupakan alasan berobat. Pseudoakromia, akibat tidak terkena sinar matahari atau kemungkinan pengaruh toksik jamur terhadap pembentukan pigmen, sering dikeluhkan penderita. Penyakit ini sering dilihat pada remaja, walaupun anak-anak dan orang dewasa tidak luput dari infeksi. Oleh karena itu agar mencegah terjadinya pitiriasis versikolor maka penting untuk dilakukan edukasi bagi penderita.

Berdasarkan kenyataan di atas maka perlu dilakukan penelitian mengenai bagaimana profil pitiriasis versikolor di poliklinik kulit dan kelamin RSUP Prof. DR. R.D. Kandou Manado periode JanuariDesember 2012.

\section{METODOLOGI PENELITIAN}

Penelitian ini merupakan penelitian deskriptif bersifat retrospektif dengan melihat dan mencatat kembali catatan rekam medik pasien pitiriasis versikolor yang tercatat di poliklinik kulit dan kelamin RSUP. Prof. Dr. R.D. Kandou Manado periode Januari - Desember 2012. Populasi mencakup semua kasus baru yang tercatat menderita penyakit kulit di poliklinik kulit dan kelamin RSUP Prof. Dr. R.D Kandou Manado periode Januari - Desember tahun 2012 dan sampel penelitian yaitu semua kasus baru yang tercatat menderita pitiriasis versikolor. Variabel penelitian yaitu jumlah kasus, jenis kelamin, umur, 
pekerjaan, warna lesi, lokasi lesi dan jenis pengobatan.

\section{HASIL PENELITIAN}

Berdasarkan penelitian deskriptif retrospektif mengenai pitiriasis versikolor di bagian Poliklinik Kulit dan Kelamin dan Instalasi Rekam Medik RSUP Prof. Dr. R.D Kandou Manado periode Januari sampai Desember 2012 maka diperoleh data berdasarkan variable sebagai berikut:

Tabel 1. Distribusi kasus pitiriasis versikolor

\begin{tabular}{llll}
\hline Tahun & $\begin{array}{l}\text { Jumlah } \\
\text { seluruh } \\
\text { kasus }\end{array}$ & $\begin{array}{l}\text { Jumlah } \\
\text { kasus }\end{array}$ & (\%) \\
\hline 2012 & 4023 & 50 & 1,24 \\
\hline
\end{tabular}

Distribusi kasus pitiriasis versikolor berdasarkan jumlah seluruh kasus baru di Poliklinik RSUP Prof. DR. R.D Kandou Manado Periode Januari- Desember 2012 adalah 50 kasus (1,24\%) dari 4023 jumlah seluruh kasus

Tabel 2. Distribusi Kasus Pitiriasis Versikolor Berdasarkan Jenis Kelamin

\begin{tabular}{lll}
\hline Jenis kelamin & $\begin{array}{l}\text { Jumlah } \\
\text { kasus }\end{array}$ & $\mathbf{( \% )}$ \\
\hline Laki - laki & 37 & 74.0 \\
Perempuan & 13 & 26.0 \\
\hline Jumlah & 50 & 100.0 \\
\hline
\end{tabular}

Distribusi kasus pitiriasis versikolor berdasarkan jenis kelamin di Poliklinik Kulit dan Kelamin RSUP Prof. DR. R.D Kandou Manado periode Januari Desember 2012 didapatkan jumlah pasien laki - laki lebih banyak daripada pasien perempuan. Jumlah pasien laki - laki sebanyak 37 pasien ( 74 \%) sedangkan jumlah pasien perempuan sebanyak 13 pasien ( $26 \%$ ).

Tabel 3. Distribusi Kasus Pitiriasis Versikolor Berdasarkan Umur

\begin{tabular}{lll}
\hline Umur & $\begin{array}{l}\text { Jumlah } \\
\text { kasus }\end{array}$ & $\mathbf{( \% )}$ \\
\hline $0-<1$ thn & 1 & 2.0 \\
$1-<5$ thn & 2 & 4.0 \\
$5-14$ thn & 6 & 12.0 \\
$15-24$ thn & 9 & 18.0 \\
$25-44$ thn & 14 & 28.0 \\
$45-64$ thn & 14 & 28.0 \\
$>65$ thn & 4 & 8.0 \\
\hline Total & 50 & 100.0 \\
\hline
\end{tabular}

Distribusi kasus pitiriasis versikolor berdasarkan umur di Poliklinik Kulit dan Kelamin RSUP Prof. DR. R.D Kandou Manado periode Januari - Desember 2012 didapatkan jumlah terbanyak pada golongan umur 25- 44 tahun dan 45 - 64 tahun masing- masing sebanyak 14 kasus ( $28 \%)$.

Distribusi kasus pitiriasis versikolor berdasarkan pekerjaan di Poliklinik Kulit dan Kelamin RSUP Prof. DR. R.D Kandou Manado periode Januari - Desember 2012 didapatkan paling banyak pasien adalah pegawai negeri sipil sebanyak 12 kasus ( $24 \%$.

Berdasarkan data di atas didapatkan bahwa warna lesi yang terbanyak yaitu lesi hipopigmentasi sebanyak 39 kasus ( 78\% ) 
Tabel 4. Distribusi Kasus Pitiriasis Versikolor Berdasarkan Pekerjaan

\begin{tabular}{lll}
\hline Pekerjaan & $\begin{array}{l}\text { Jumlah } \\
\text { kasus }\end{array}$ & $\mathbf{( \% )}$ \\
\hline Wiraswasta & 8 & 16.0 \\
$\begin{array}{l}\text { Pegawai } \\
\text { Negeri sipil } \\
\text { Pensiunan }\end{array}$ & 12 & 24.0 \\
$\begin{array}{l}\text { Ibu Rumah } \\
\text { Tangga } \\
\text { Mahasiswa }\end{array}$ & 6 & 8.0 \\
$\begin{array}{l}\text { Siswa } \\
\text { Petani }\end{array}$ & 3 & 12.0 \\
$\begin{array}{l}\text { Tidak } \\
\text { diketahui }\end{array}$ & 3 & 6.0 \\
\hline Total & 50 & 6.0 \\
\hline
\end{tabular}

Tabel 5. Distribusi Kasus Pitiriasis Versikolor Berdasarkan Warna Lesi

\begin{tabular}{lll}
\hline Warna Lesi & $\begin{array}{l}\text { Jumlah } \\
\text { Kasus }\end{array}$ & $\mathbf{( \% ) ~}$ \\
\hline Hipopigmentasi & 39 & 78.0 \\
Hiperpigmentasi & 5 & 10.0 \\
Eritematous & 6 & 12.0 \\
\hline Total & 50 & 100.0 \\
\hline
\end{tabular}

Distribusi pasien pitiriasis versikolor berdasarkan lokasi lesi di Poliklinik Kulit dan Kelamin RSUP Prof. DR. R.D Kandou Manado periode Januari - Desember 2012 didapatkan sebanyak 30 kasus ( 60\% ) memiliki lesi kombinasi ( terdapat di beberapa tempat seperti wajah, badan dan ekstremitas.

Distribusi kasus pitiriasis versikolor berdasarkan jenis pengobatan di Poliklinik Kulit dan Kelamin RSUP Prof. DR. R.D Kandou Manado periode Januari -
Desember 2012 didapatkan sebanyak 36 pasien (72\% ) mendapat terapi kombinasi ( antijamur oral dan antijamur topikal .

Tabel 6. Distribusi Kasus Pitiriasis Versikolor Berdasarkan Lokasi Lesi

\begin{tabular}{lll}
\hline Lokasi lesi & $\begin{array}{l}\text { Jumlah } \\
\text { Kasus }\end{array}$ & $(\%)$ \\
\hline Wajah & 6 & 12.0 \\
Badan & 6 & 12.0 \\
$\begin{array}{l}\text { Ekstremitas } \\
\text { atas }\end{array}$ & 5 & 10.0 \\
$\begin{array}{l}\text { Ekstremitas } \\
\text { bawah }\end{array}$ & 3 & 6.0 \\
Kombinasi & 30 & 60.0 \\
\hline Total & 50 & 100.0 \\
\hline
\end{tabular}

Tabel 7. Distribusi Kasus Pitiriasis Versikolor Berdasarkan Jenis Pengobatan

\begin{tabular}{lll}
\hline $\begin{array}{l}\text { Jenis } \\
\text { Pengobatan }\end{array}$ & $\begin{array}{l}\text { Jumlah } \\
\text { Kasus }\end{array}$ & $\mathbf{( \% ) ~}$ \\
\hline Antijamur oral & 1 & 2.0 \\
$\begin{array}{l}\text { Antijamur } \\
\text { topikal }\end{array}$ & 13 & 26.0 \\
$\begin{array}{l}\text { Kombinasi } \\
\text { Total }\end{array}$ & 36 & 72.0 \\
\hline
\end{tabular}

\section{BAHASAN}

Pada penelitian ini, sampel yang diambil ialah seluruh kasus baru pitiriasis versikolor yang berobat di Poliklinik Kulit dan Kelamin RSUP Prof. DR. R.D Kandou Manado periode Januari sampai Desember 2012.

Berdasarakan data pada tabel 1 total kunjungan pasien baru di Poliklinik Kulit dan Kelamin RSUP Prof. DR. R.D Kandou Manado periode Januari sampai Desember 
2012 adalah 4023 kasus dan ditemukan 50 kasus pitiriasis versikolor (1,24\%). Angka ini masih tergolong jauh lebih rendah dibandingkan angka insidens pitiriasis versikolor di RSUD Dr.Soetomo Surabaya tahun 2005 yaitu mencapai yaitu 13,3\% dari seluruh kasus baru. ${ }^{3}$ Kemungkinan hal ini disebabkan karena faktor predisposisi di kota Surabaya lebih tinggi dibanding kota Manado.

Dari 50 kasus pitiriasis versikolor, jumlah pasien laki - laki ditemukan lebih banyak di bandingkan pasien perempuan yaitu 37 kasus ( $74 \%$ ) laki-laki dan 13 kasus ( $26 \%)$ perempuan dengan perbandingan antara laki-laki dan perempuan $2,8: 1$. Hasil penelitian ini juga sejalan dengan penelitian yang dilakukan oleh Agung Satria, Gatha S, Rao dan Jena et al, yang mendapatkan hasil bahwa pasien pitiriasis versikolor lebih banyak ditemukan pada laki-laki dibandingkan pada perempuan. ${ }^{4-6}$ Hal ini diduga karena laki-laki mempunyai aktivitas fisik diluar rumah lebih banyak dibandingkan perempuan sehingga lebih sering berada di suhu tinggi. Dan juga mungkin berkaitan dengan jenis pekerjaan. ${ }^{7}$

Ditinjau dari segi umur, dari penelitian ini kasus pitiriasis versikolor terbanyak ditemukan pada usia 25-44 tahun. Sementara hasil penelitian dari Satya W bahwa frekuensi tertinggi terdapat pada kelompok umur 15- 24 tahun . Sedangkan menurut Kusmarinah B et al, mengatakan bahwa pada laki-laki terbanyak dijumpai pada usia 21-25 tahun dan perempuan terbanyak dijumpai pada usia 26-30 tahun. ${ }^{8}$ Pada dasarnya pitiriasis versikolor tidak menyerang kelompok umur tertentu dan dapat terjadi dalam semua kelompok umur, walaupun sebagian besar hasil penelitian mendapatkan hasil bahwa kebanyakan pitiriasis versikolor terjadi pada usia dewasa. Hal ini mungkin berkaitan dengan aktivitas sehari- hari dari kelompok umur dewasa yang lebih sering terpajan sinar matahari . Selain itu pada kelompok umur dewasa kelenjar sebaseus lebih aktif memproduksi lemak pada kulit sehingga kelompok umur ini sebagian besar memiliki kulit yang berminyak. ${ }^{9}$

Kelompok yang paling banyak didiagnosis pitiriasis versikolor adalah kelompok dengan pekerjaan Pagawai Negeri Sipil ( PNS) yaitu sebanyak 12 pasien ( $24 \%$ ) . Berbeda dengan hasil penelitian dari Ali ZM et al, yang mendapatkan hasil bahwa kelompok yang paling banyak di diagnosa pitiriasis versikolor adalah kelompok pelajar. ${ }^{10}$ Kelompok pekerjaan PNS paling banyak ditemukan kemungkinan karena penderita yang datang berobat merupakan kelompok PNS yang bekerja di luar ruangan, bukan didalam ruangan. Menurut Jurnal Kesehatan dan Kedokteran Universitas Sriwijaya, hubungan antara pekerjaan dan timbulnya pitiriasis versikolor mungkin dipengaruhi oleh lingkungan kerja yang panas dan lembab serta pakaian pelindung yang menyebabkan banyak keringat. ${ }^{11}$

Berdasarkan warna lesi yang pada pasien pitiriasis versikolor yang paling banyak ditemukan adalah lesi hipopigmentasi dengan jumlah 39 kasus. Menurut Aljabre S et al, secara umum pitiriasis versikolor diduga menyebabkan lesi hipopigmentasi pada individu dengan kulit lebih gelap dan lesi hiperpigmentasi pada individu dengan kulit lebih putih. Namun pandangan ini belum resmi diteliti. $^{12}$ Orang Indonesia berkulit kuning langsat sampai kecokelatan, hal ini juga berkaitan dengan lesi hipopigmentasi merupakan lesi yang paling banyak ditemukan pada penelitian kali ini

Berdasarkan hasil penelitian kali ini, 
dari data 50 kasus didapatkan bahwa pitiriasis versikolor paling banyak menyerang lokasi lesi kombinasi ( terdapat di beberapa tempat seperti wajah, badan dan ekstremitas) sebanyak 30 kasus ( 60\%). Hasil penelitian ini sejalan dengan hasil penelitian yang dilakukan oleh Ali Z et al, yang mengemukakan bahwa lokasi predileksi terbanyak pada penderita pitiriasis versikolor di daerah badan yaitu dada dan punggung sedangkan pada penderita anak-anak dan remaja lebih sering terkena di daerah wajah. ${ }^{10}$ Lesi kombinasi paling banyak ditemukan mungkin disebabkan karena banyak penderita yang kurang memperhatikan dan tidak mendapatkan terapi saat awal munculnya pitiriasis versikolor sehingga lesi meluas ke beberapa bagian tubuh. Hal ini berkaitan dengan pitiriasis versikolor pada umumnya tidak memberikan gejala.

Pada penelitian ini juga didapatkan hasil bahwa jenis pengobatan yang paling banyak diberikan kepada pasien adalah terapi kombinasi (antijamur oral dan antijamur ropikal ) dengan jumlah 36 kasus. Terapi kombinasi ini diberikan karena mengingat kekerapan dan kesulitan edukasi untuk memanipulasi faktor lingkungan (eksogen) ataupun faktor endogen yang berperan sebagai predisposisi yang sangat mungkin bervariasi untuk masing-masing pasien. Sedangkan penggunaan obat topikal diberikan kepada pasien dengan lesi terbatas. Penggunaan obat sistemik umumnya lebih dianjurkan untuk kasus yang sering kambuh atau kurang bresponsif terhadap obat topikal saja. Apapun terapi yang diberikan, pitiriasis versikolor sering kambuh. Pengobatan lebih ditujukan untuk mengontrol infeksi daripada penyembuhan., 8

\section{SIMPULAN}

Dari hasil penelitian retrospektif penderita pitiriasis versikolor di Poliklinik Kulit dan Kelamin RSUP Prof.DR. R.D Kandou Manado periode Januari Desember 2012 dapat disimpulkan jumlah pasien pitiriasis versikolor di Poliklinik Kulit dan Kelamin RSUP Prof.DR. R.D Kandou Manado periode Januari Desember 2012 sebanyak 50 pasien ( 4,96 \% ) dari 4023 kasus baru , lebih banyak ditemukan pada laki-laki dibandingkan perempuan, umur 25- 44 tahun dan 45 - 64 tahun merupakan kelompok umur yang terbanyak, Pegawai Negeri Sipil ( PNS ) adalah kelompok pekerjaan yang paling banyak menderita pitiriasis versikolor, warna lesi yang paling banyak ditemui adalah makula hipopigmentasi, lokasi lesi terbanyak ditemukan di badan, kemudian diikuti oleh wajah, ekstremitas atas dan ekstremitas bawah, jenis pengobatan yang paling banyak diberikan adalah terapi kombinasi ( antijamur oral dan antijamur topikal) .

\section{SARAN}

Kelengkapan data pasien di catatan rekam medik dan buku register di bagian instalasi rekam medik dijaga dengan baik agar data yang diperoleh lebih akurat. Perlu dilakukan penelitian lebih lanjut mengapa pitiriasis versikolor lebih sering terkena pada laki-laki dibandingkan perempuan. Perlu dilakukan penelitian lebih lanjut tentang hubungan pekerjaan dengan pitiriasis versikolor.Perlu penelitian angka prevalensi pitiriasis versikolor pada tahun tahun berikutnya, agar dapat diketahui angka prevalensi pada setiap tahunnya.

\section{DAFTAR PUSTAKA}

1. Rai, Mahendra K., Wankhade S., Tinea versicolor an epidemiology . Journal of 
Microbial \& Biochemial Techonology. 2009 [cited 2014 October]; Available from : http://www.omicsonline.org

2. Dr.M Fattah. Infeksi jamur kulit. In: Ilmu penyakit kulit. $1^{\text {st }}$ ed. Penerbit Hipokrates ; Harahap Marwali. Jakarta 2000. p.73-4

3. Hidayati AN, Suyoso S, Hinda DP, Sandra E. Mikosis superfisialis di divisi mikologi unit rawat jalan penyakit kulit dan kelamin RSUD. Dr. Soetomo Surabaya tahun 2003-2005. p.1-3

4. Radisu AS. Distribusi kejadian tinea versikolor pada anak sekolah dasar negeri (SDN) 53 sungai raya kabupaten Kubu raya berdasarkan karateristik dan faktor resiko. 2012

5. Rao, G.S., et al. Clinico-epidermiological studies on tinea versicolor. Indian Journal of Dermatology, Venerology, and Leprology 2002; 68 : 208-9

6. Jena DK, Sengupta S, Dwari BC, Ram MK. Pityriasis versicolor in the pediatric age group. Indian Journal of Dermatology, Venereology, and Leprology 2005; 71: 259-61

7. Kyriakis KP, Terzoudi S, Palamaras I, Pagana G, Michailides C, Emmanuelides S. Pityriasis versicolor prevalence by age and gender. Mycoses . 2006 ; 49 ; 517-8

8. Bramono S, Suyoso S, Radiono S. Pitiriasis versikolor. In : Dermatomikosis superfisialis. $2^{\text {nd }}$ ed. FKUI ; 2013 . p.24- 32

9. Goldsmith L.A, Kats S.I, Gillchrest BA, Paller AS, Leffell DJ, Wolff $\mathrm{K}$. Fitzpatrick's Dermatology in General Medicine, $8^{\text {th }}$ ed. E-book : The McGraw-Hill companies.New York 2012. p. $2298-311$

10. Ali ZM, Zahra M, Majid Z. Pityriasis versicolor in Ahvaz, Iran. Jundishapur journal of microbiology. 2009 ; 2 (3) p.92

11. Jurnal Kedokteran dan Kesehatan . Publikasi ilmiah fakultas kedokteran Universitas Sriwijaya. 2008 : p.2330

12. Aljabre SHM, Alzayir AAA, Abdulghani M, Osman OO. Pigmentary Changes of tinea versicolor in dark - skinned patients. International Journal of Dermatology. 2001; 40:273

13. Gaitanis G, Magiatis $P$, Hantschke M, Bassukas ID, Velegrakid A. The Malassezia genus in skin and systemic diseases. Clin Microbiol Rev. 2012;25 106-41 